\title{
Techniques, Knowledge and Know-how Mosaic Stucco Brick Ceramic
}

\author{
Ahmed M. Al-Baghil* \\ *(The public Authority for Applied Education and Training, Kuwait,
}

\begin{abstract}
At that time was the most immediate visual testimony of this civilization. Islamic architecture preserved those characters, which distinguish it from other architecture traditions. The study of major Islamic edifices demonstrates that the organization of volumes and spaces in Islamic architecture often responds to geometric orders. The art of ceramic mural introduced color to Iranian and Central Asian architecture as the beginning of the $12^{\text {th }}$ century. This polychrome dominated by turquoise blue lifted reality into an image of divines.
\end{abstract}

\section{Splendor of Islam}

Each topic is presented through a number of outstanding examples from all over the Islamic world as Taj mahal and Alhambra. The organization of labor in the field of construction was dedicated by highly specialized system. Another character is the geographical mobility; the mobility could also be provoked by political upheaval. One of the main construction techniques inherited by Umayyad builders was stonemasonry; this consists of precise cutting and shaping of stone blocks. Furthermore, one of the simplest techniques already used in Assyrian and Achaemenid Arch consists of alternating layers of stone and bricks, which could be found in the elements of the Great Mosque of Hama in Syria, another ornamental technique connected with stone construction are sculpture such as: Mshatta. The technical principle is based on hollowing out the material rather than modeling.

\section{Figures and Tables}

1.

ursive calligraphic band on a scrolled background on Ben Yasuf madrasa in Marrakesh (1564-65).

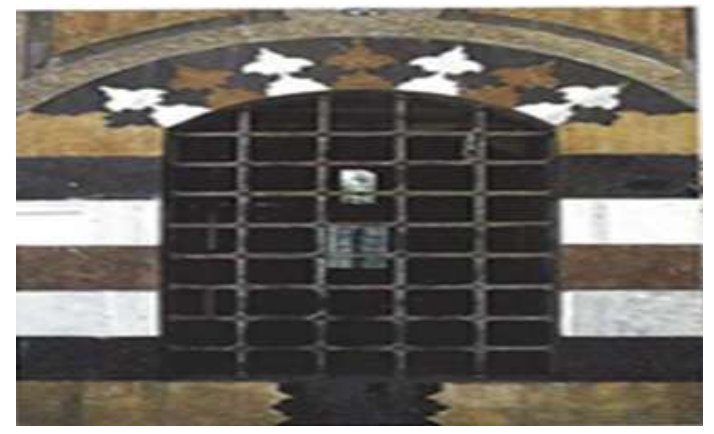

2. Detail of column of the Cifte Minareli madrasa in Erzurum (1253). This particularly unfinished sculpted ornamentation displays the different stages of the work. The original stone surface on which the principle lines of the décor were traced is carved out in such a way to create a flat background. This type of sculpture associated with interlace patterns gives the impression that the mural surface is covered with fabric.

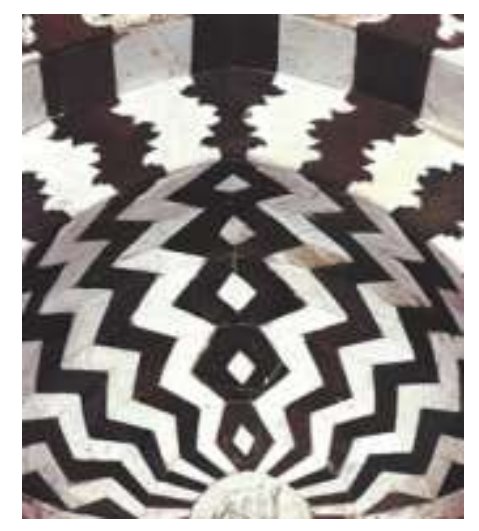

The most common and defining materialfor Muslim building culture was Stucco as described by (Ruba 189). Plaster was disregarded in the contemporary history of the Islam architecture as poorin relation to materials for a considerable number of reasons like its lack of applications in building works that are heavy duty, its flexibility, and simplicity in forming rock mineral (Rook 200). However, skilled Muslim artisans have managed to implement the technique to create several impressive designs and buildings in stucco that have survived to date. The Mosaic Stucco Brick Ceramic played a crucial role in Islam architecture as most of their architectural structures and designs implemented the technique. Therefore, it is important to understand the techniques, knowledge, and know-how behind the working and creation of stucco.

According to Francis, the mosaic design implemented the use of plaster to create the Dome of the Shah Mosque in a time when architectural decoration was the most predominant factor amongst 
Islam community (160). Architects used several techniques to decorate most religious monuments as well as other secular complexes with the help of techniques and styles that reflected the religious belief of the Islamist society. The art of using decorative techniques like molded stucco or brickwork increased in the Muslim culture as other Islam communities from the east and the mosaics inherited this culture.

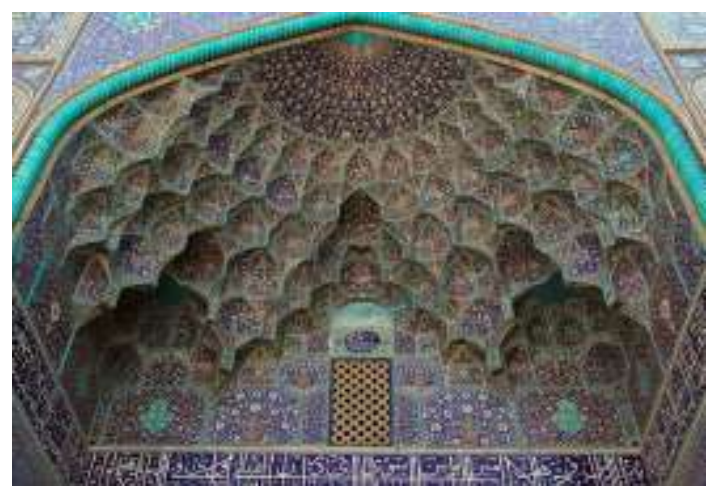

Detail of the Mugarnas Vault, entrance portal of the Masjid-I Shah, Isfahan, Iran. Built during the early $17^{\text {th }}$ century. Known as Masjid-I Imam now because of the current government 's aversion to the monarchy.

The production of stucco was as a result of a harsh climatic condition in the Mediterranean regions. The hot and dry climates promoted the emergence of gypsum which became accessible and was widely used in decorating buildings. It is the gypsum rock that represents stucco in both its natural state the commercially obtained material. Gypsum can be prepared for use by heating it at temperatures between $120^{\circ} \mathrm{C}$ and $100^{\circ} \mathrm{C}$ (Ruba 189). The heat causes the mineral to crystallize hence making it ready to be used for architectural and other decorative purposes.

All works based on gypsum undergo various changes and phases during the mixing. These faces influence the final formation of stucco. Hence, they cannot be broken. The first formation step involves the transformation of gypsum into hydrated calcium sulfate. The phase occurs due to the minerals' contact with water. The amount of water added in this process determines how hard the plaster will be. The final stage involves crystallization through an exothermic reaction and transformation of the crystals into a network. These transformations that lead to the formation of stucco provide a substantial explanation to the high pricing of the product.

There are limits to the use of plaster in the construction industry in Islamic society. For example, it should be utilized in outdoor construction in areas with limited rainfall while it should be used indoors for humid areas. Most Masons understood the working of stucco hence they always covered it with a protective layer composed of calcium sulfate to make the element harder, to eliminate chances of corrosion and to reduce porosity. Most artisans appreciated the use of stucco in building and decoration hence they found it necessary to protect its layer from agents of corrosion.

Stucco formed a basic part of architectural designs and buildings in mosaic communities as it was used to build both religious and secular complexes. The technique gained its popularity in the Islam society and has since then been used in wider perspectives. The high price of stucco can be attributed to its formation process from gypsum which most artisans refer to as adaptable and flexible. There are still other techniques about the Mosaic stucco that can to be explored.

In conclusion, all the techniques of mosaic employed were used in the Umayyad period, created by Byzantine craftsman. Although this technique produced masterpieces, it was to play only a minor role in the following years to embellish the mihrab of Great Mosque of Cordoba and it appears in several buildings in Damascus in $13^{\text {th }}$ and $14^{\text {th }}$ century. The sculpture's work brings the original plane of the wall into a play, giving its ornamentation the appearance of finely woven textile covering.

\section{Works Cited}

[1]. Ching, Francis DK. A visual dictionary of architecture. John Wiley \& Sons, 2011.

[2]. Kana'an, Ruba. "Architectural Decoration in Islam: History and Techniques." Encyclopaedia of the History of Science, Technology, and Medicine in Non-Western Cultures. Springer Netherlands, 2008. 187199.

[3]. Rook, Tony. Roman building techniques. Amberley Publishing Limited, 2013. 